\title{
Health labs focus on mystery pneumonia
}

David Cyranoski, Tokyo

The World Health Organization (WHO) is coordinating a massive international investigation into a mysterious pneumonia-like disease that may have originated in the southern Chinese province of Guangdong.

On 17 March, the WHO announced that 11 laboratories in 10 countries would collaborate in an attempt to identify the cause of severe acute respiratory syndrome (SARS). The disease, which begins with a fever, cough and shortness of breath, can develop into a pneumonia-like condition that in some cases results in death.

As of 18 March, global health authorities outside China had reported 182 cases of SARS and four deaths across Hong Kong, Canada, Singapore, Taiwan, Germany, Switzerland and Thailand. The WHO took the rare step on 15 March of branding the outbreak "a worldwide health threat".

It remains unclear whether the first reported cases of SARS, in Vietnam and Hong Kong in late February, are related to more than 300 similar cases of atypical pneumonia that began last November in Guangdong and reportedly peaked in early February.

"The clinical picture is very similar, but absolute linkage with the Guangdong cases cannot be made at this time," says Masato Tashiro, director of the WHO's collaborating centre for influenza at the National Institute of Infectious Diseases (NIID) in Tokyo. Tashiro met with health officials in Beijing earlier this month to discuss the Chinese outbreak. But Klaus Stöhr, director of the WHO's global influenza network, says that the timing and clinical similarities "would be too much of a coincidence for the outbreaks not to be linked".

Whether the cause of SARS is bacterial or viral is still unknown. Laboratories initially

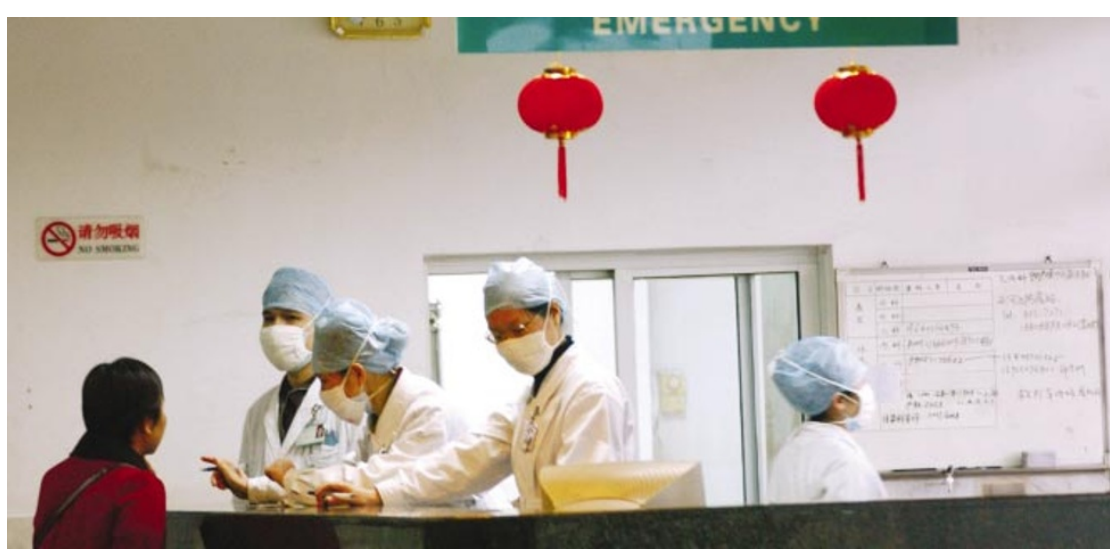

Protection is being stepped up at Hong Kong's hospitals after cases of an unusual respiratory syndrome.

looked for stretches of genetic sequence associated with known agents in samples taken from patients. Tashiro, for instance, has been searching for the RNA of the influenza virus in blood serum from patients in Hanoi, using a method called the reverse-transcriptase polymerase chain reaction.

This method converts any viral RNA present into DNA. It then uses primers - short DNA sequences that match the DNA in certain viruses or viral families - to bind to the DNA strand and start copying it, making enough copies for the strand to be identified.

That will only happen if the particular virus is present, and Tashiro's samples did not find the influenza virus. But the RNA could have degraded and become undectable in the week it took for the samples to reach Tashiro's lab. It is also possible that a virus could have mutated so that the primers cannot detect it.

Tests on samples taken in Hong Kong have identified one type of influenza virus and a respiratory syncytial virus - but neither has the virulence to explain the outbreak, investigators say. The same tests seem to rule out any significantly virulent influenza, including the $\mathrm{H} 5 \mathrm{~N} 1$ avian flu virus that infected a family in Hong Kong earlier this year (see Nature 422, 6; 2003).

Having ruled out many initial ideas about specific agents, laboratories collaborating in the WHO effort, including the NIID and the Centers for Disease Control and Prevention in Atlanta, Georgia, are undertaking a broader, more systematic search. They will start by using less-specific primers that can identify larger virus families.

Researchers are also delving into records of the Chinese outbreak. China, which has been strongly criticized internally and externally for its failure to provide more information when the outbreak first occurred, has now invited a WHO team to visit Guangdong. The team was expected to arrive there this week. But some health officials are already asking if the delay in access may have contributed to the spread of the disease.

\section{Chicken flu races through Dutch poultry farms}

\section{Alison Abbott}

The Netherlands is this week counting the cost of the latest outbreak of avian flu. The flu, which is sweeping through the country's chicken flocks, has already infected more than $\mathbf{5 0}$ farms and resulted in the culling of over 2 million chickens.

The economic implications of the outbreak, which began on 28 February, are severe - the Netherlands is Europe's largest exporter of chickens. But the cost could have been much greater.

Initial fears that the disease was linked to cases of avian flu in Hong Kong (see Nature 422,6 ; 2003) were quashed early on, thanks to the rapid detective work of a team at
Erasmus University in Rotterdam. The Hong Kong strain, known as H5N1, sparked widespread alarm after it killed a man and infected other members of his family.

Within 48 hours of receiving samples of the virus that caused the Dutch outbreak, the Rotterdam team had identified it as an H7N7 strain, revealing that its genetic characteristics are similar to those of a strain identified in mallard ducks in 2000.

Nevertheless, the Dutch virus can infect humans, and as of 18 March it had caused conjunctivitis in at least 32 people, some of whom have flu-like symptoms. Anxious researchers are not ruling out the possibility that the chicken flu could trigger a human flu pandemic. But for this to happen, the virus would have to infect someone infected with a normal human flu virus, so that the two strains could swap genes to produce a more virulent humanized virus.

This is thought to be highly unlikely. But to reduce any chances of such co-infection, Dutch doctors are pursuing aggressive drug treatment of those infected, in an attempt to reduce their viral load.

Avian flu outbreaks are rare, but can kill entire flocks in a few days. Transmission of the virus from wildfowl to domestic chickens may have occurred through free-range hens that spend time outdoors, suggests Albert Osterhaus, who heads the Rotterdam team. 